
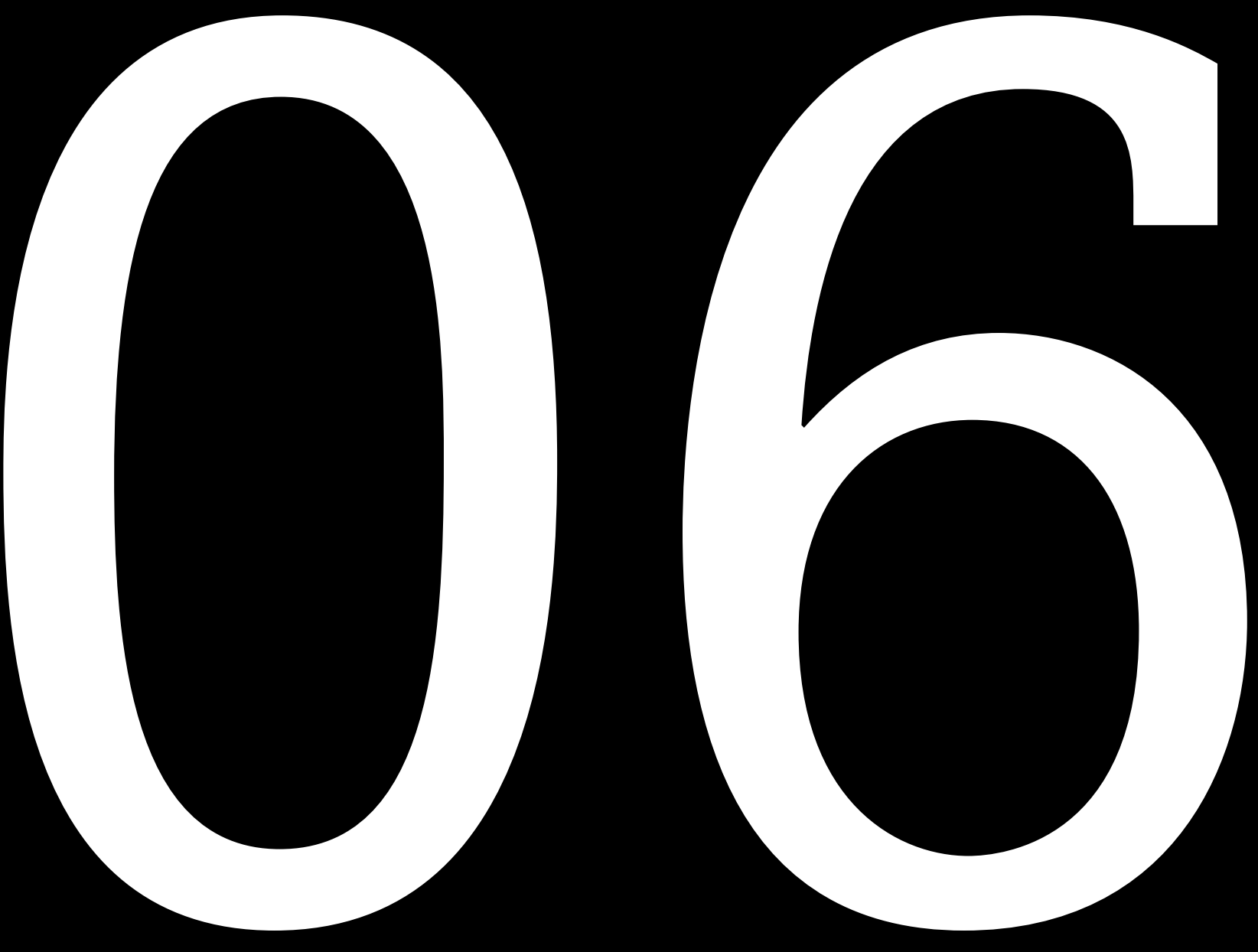

DOI: https://doi.org/10.14483/2422278X.14700 


\section{Reclutamiento forzado: una cara del juvenicidio en Colombia ${ }^{1}$}

Forced recruitment: A viewpoint on juvenicide in Colombia

Recrutamento forçado: uma face do juvenicídio na Colômbia

\section{Paola Andrea Díaz Bonilla ${ }^{2}$}

Para citar este artículo: Díaz, P. (2019). Reclutamiento forzado: una cara del juvenicidio en Colombia. Ciudad Paz-ando, 12(2), 75-85. doi: https://doi.org/10.14483/2422278X.14700

Fecha de recepción: 29 de marzo de 2019

Fecha de aprobación: 7 de octubre de 2019

\footnotetext{
1 Artículo de reflexión derivado del trabajo de grado realizado para optar el grado de la especialización en Políticas Públicas para la Igualdad de América Latina y el Caribe, Clacso, Flacso Brasil y UMET.

2 Psicóloga, Universidad Pedagógica y Tecnológica de Colombia; especialista en Acción Sin Daño y Construcción de Paz, Universidad Nacional de Colombia; especialista en Políticas Públicas para la Igualdad de América Latina y el Caribe, Flacso Brasil; candidata a magíster en Historia y Memoria de la Universidad Nacional de La Plata; doctoranda en Estudios de Género, Universidad Nacional de Córdoba. Consultora en temas de género, derechos humanos y paz. Correo electrónico: pandreadiazb@gmail.com, ORCID: http://orcid.org/0000-0003-2127-8709
} 


\section{RESUMEN}

El reclutamiento forzado en Colombia, como hecho social que afecta a amplios sectores de la juventud, cumple varias condiciones enmarcadas dentro de la categoría del juvenicidio. El artículo plantea una serie de reflexiones a partir de las voces de cuatro jóvenes víctimas de este hecho, quienes con sus testimonios reflejan la relación persistente entre desigualdad social, vulnerabilidad y pobreza, como factores que anteceden a esta forma de victimización en el marco del conflicto armado. Por último, se identifican distintos aspectos de la vida armada que sirven de escenario para el juvenicidio de un particular fragmento de esta población: jóvenes pobres, excluidos socialmente y sin recursos para construir proyectos de vida alternos a la violencia.

Palabras clave: conflicto armado, desigualdad social, jóvenes, juvenicidio, reclutamiento forzado.

Forced recruitment in Colombia, as a social reality that affects the youth, fulfils several conditions defined within the category of juvenicide. This article provides a series of reflections formulated on the basis of voices of four young victims of this harsh reality; their testimonies exhibit the enduring relationship between social inequality, vulnerability and poverty as factors that precede such form of victimization within the armed conflict's context. Finally, the authors identify different aspects of armed life that serve as an environment for juvenicide from a particular segment of the population, particularly, the poor young people who are socially excluded and lack resources to build and live their lives apart from violence.

Keywords: armed conflict, social inequality, young people, juvenicide, forced recruitment.
O recrutamento forçado na Colômbia, como um fato social que afeta amplos setores da juventude, cumpre várias condições enquadradas dentro da categoria de juvenicídio. $\mathrm{O}$ artigo apresenta uma série de reflexões baseadas nas vozes de quatro jovens vítimas desse fato, que com seus testemunhos refletem a persistente relação entre desigualdade social, vulnerabilidade e pobreza, como fatores que antecedem essa forma de vitimização no marco do conflito armado. Finalmente, são identificados diferentes aspectos da vida armada que servem de cenário para o juvenicídio de um fragmento particular dessa população: jovens pobres, socialmente excluídos e sem recursos para construir projetos de vida alternativos à violência.

Palavras-chave: conflito armado, desigualdade social, jovens, juvenicidio, recrutamento forçado. 


\section{Introducción}

El reclutamiento forzado en Colombia ha sido un flagelo de alto impacto en la vida de niños, niñas, adolescentes (NNA) y jóvenes ${ }^{3}$ vulnerables. El punto de partida de la reflexión en este artículo surge de que la vinculación directa de esta población al conflicto armado acentúa dramáticamente los múltiples riesgos psicosociales que históricamente han obstaculizado el desarrollo pleno de la juventud y el goce efectivo de sus derechos. Encontrar las variadas relaciones estructurales que operan como ejes articuladores en la práctica del reclutamiento forzado es uno de los propósitos de esta indagación, las cuales están matizadas a partir de las experiencias de cuatro jóvenes excombatientes, vinculados entre los doce y catorce años al conflicto armado.

Lo que se propone en este texto es problematizar la vulnerabilidad y desigualdad social que rodea al reclutamiento forzado de jóvenes a organizaciones armadas ilegales, ello en el entramado de las lógicas guerreras, concluyendo lo que se ha denominado el juvenicidio de esta población (Valenzuela, 2015). Este último es un concepto reciente, acuñado como respuesta explicativa al exterminio sistemático de sectores concretos de la juventud de América Latina, cuyo soporte resulta de la comprensión sobre la "complejidad de las fragilidades que expresa la intersección entre condición etaria, generacional y de clase" (Llovet, 2015, p. 194).

No obstante, retomar la categoría de juvenicidio tiene la pretensión de visibilizar la muerte impune de los y las jóvenes, y, a su vez, encarar este hecho social a la luz de los procesos de precarización social y económica que envuelven a vastos segmentos de la población juvenil, los cuales, acentuados por la estigmatización y criminalización, suelen ejercer distintas formas de violencia simbólica, desacreditando sus identidades; un mecanismo eficaz en la legitimación de dichos asesinatos. Por todo esto, las causas estructurales de inequidad y exclusión que preceden al juvenicidio amplían el espectro con que dicho fenómeno se expresa en la vida de los y las jóvenes, constituyéndose así un juvenicidio gota a gota (Muñoz, 2015).

Cabe mencionar que la vulnerabilidad socioeconómica que afecta a los jóvenes en Colombia es elocuente. Según el Sistema Nacional de Información en Juventud y Adolescencia en Colombia (Juaco) en el país actualmente hay 12757040 jóvenes, de los cuales el 16,67\% son desempleados. Si las cifras encontradas reflejan la dramática

3 Según la Convención sobre los Derechos del Niño, se encuentran definidos como los menores de 18 años. Para esta investigación se empleará el termino genérico joven de acuerdo con la definición de la Ley 1622 de 2013, la cual define como toda persona entre 14 y 28 años (Artículo 5, Numeral 1); asimismo, este rango es acorde a lo que establece Naciones Unidas (A/36/215, para. 8 del anexo) y que corresponde a las edades en que los y las jóvenes participantes de este estudio fueron reclutados. realidad juvenil a nivel nacional, estas se intensifican al focalizarse en jóvenes rurales; así, el Censo Nacional Agropecuario de 2014 señala que el índice de pobreza multidimensional en el campo es del $44,7 \%$, el doble del registro total nacional $(21,9 \%)$ y casi tres veces mayor al urbano (15,4\%). Por otra parte, el estudio identificó que el $72,6 \%$ de los jóvenes entre diecisiete y veinticuatro años no tenía acceso a la educación y el 11,5 \% de la población campesina mayor de quince años no sabe leer ni escribir (Revista Semana, 2015).

Al realizar una aproximación al fenómeno de reclutamiento forzado en Colombia, el panorama es preocupante por su persistencia y sistematicidad, siendo una práctica de guerra empleada por todos los actores armados que ha prevalecido a lo largo del conflicto. Fuentes de instituciones del Estado ofrecen diferentes estadísticas de la problemática en cuestión, el programa especializado de atención a niños, niñas y adolescentes que se desvinculan de grupos armados al margen de la ley del Instituto Colombiano de Bienestar Familiar (ICBF) reportó la recepción de 5156 desvinculados desde noviembre de 1999 a marzo de 2013, mientras el Registro Único de Víctimas de la Unidad para las Víctimas estableció, a octubre de 2019, la vinculación de 8188 niños, niñas y adolescentes. Finalmente, el Observatorio de Memoria y Conflicto del Centro Nacional de Memoria Histórica (2019) indica que entre 1958 y 2018 fueron reclutados 17778 NNA, de los cuales solo 6750 casos (38\%) cuentan con un presunto responsable, mientras que 11028 casos (62\%) fueron reclutados por autores no identificados.

La disparidad en el número de jóvenes enlistados demuestra la falta de claridad sobre la real incidencia del reclutamiento en Colombia y sus expectativas de disminuir, pues lejos de ser un fenómeno tendiente para acabar, la perspectiva es su persistencia por los riesgos presentes en los contextos sociales que habitan los jóvenes y la diversificación de actores armados. Esta realidad ha sido analizada por distintas organizaciones de derechos humanos, quienes prevén un aumento de ese delito por el fortalecimiento y expansión de las Bandas Criminales y las disidencias de las Farc-Ep (Fuerzas Armadas Revolucionarias de Colombia, Ejercito del Pueblo) debido a la ocupación de los territorios dejados por esta guerrilla, ello luego de la firma del Acuerdo de Paz con el Gobierno de Juan Manuel Santos.

Esta investigación cualitativa se llevó a cabo empleando el paradigma metodológico interpretativo de tipo biográfico, ello con el fin de permitir:

la búsqueda de determinantes en la construcción de una vida, pero al mismo tiempo posibilita la búsqueda de sentidos a partir de las vivencias, es decir, la comprensión de la manera como el individuo habita esa historia en los planos afectivo, emocional, cultural y social. (Correa, 1999 , p. 41) 
La técnica de recopilación de los relatos de vida de los jóvenes se llevó a cabo a través de la entrevista, desarrollando tres encuentros con cada participante. Por último, el contacto con los jóvenes se logró debido a que todos se encontraban en el programa de reintegración social de la Agencia para la Reincorporación y la Normalización (ARN) en calidad de desvinculados del conflicto armado.

Teniendo como marco el contexto expuesto, el escrito se encuentra articulado a cuatro relatos de vida de jóvenes, dos mujeres y dos hombres, que hicieron parte de grupos armados ilegales ${ }^{4}$ de organizaciones guerrilleras y paramilitares durante varios años de sus vidas. Los participantes en su totalidad son de origen campesino, oriundos de los departamentos de Santander y Boyacá, donde también fueron enlistados; asumieron en estas estructuras armadas roles como patrulleros y guerrilleros rasos, operando en diversas regiones del país como los Llanos Orientales, el Caribe y el Magdalena Medio. Respecto a algunas características, es posible citar que tres de los cuatro jóvenes provenían de familias disfuncionales con presencia de violencia intrafamiliar y una estructura nuclear y monoparental; frente al nivel educativo, solo una de las jóvenes se encontraba cursando octavo grado, mientras que los demás no habían culminado la formación de básica primaria.

Es necesario anotar que el alcance de los cuatros testimonios empleados no tiene la pretensión de generalización. El interés radica en identificar a partir de sus trayectorias vitales una serie de factores contextuales y de orden estructural que son susceptibles de conducir al juvenicidio simbólico, físico o gota a gota representado en el reclutamiento forzado. Las líneas de este escrito, por tanto, destacan la voz protagónica de los participantes de esta investigación; en este proceso reflexivo, sus vivencias son el camino que traza el análisis aquí contenido.

En el primer apartado, se establece la relación vulnerabilidad y reclutamiento forzado, demarcando las condiciones que antecedieron la vinculación de los jóvenes participantes; los resultados evidencian las carencias materiales, afectivas y de índole psicosocial que estuvieron presentes en su infancia, como factores que mediaron de gran modo en su involucramiento. La huella indeleble de la desigualdad y marginalidad en las experiencias de vida sirven como punto de partida en el análisis de lo que podría entenderse como un juvenicidio gota a gota, fenómeno que va acumulando distintos factores sociales, económicos y culturales que precipitan la trasformación de estos jóvenes en actores obligados de la guerra.

El análisis continúa teniendo como referente la vida armada y cotidianidad de estas estructuras al margen de la ley como escenario del juvenicidio. El ámbito donde la aplicación de un conjunto de dispositivos bio

4 Por decisión expresa de dos jóvenes participantes se omite el nombre del grupo armado ilegal del que hicieron parte. y necropolíticos van conminando a los jóvenes a una condición de sujetos descartables, cuya posición de guerreros-objeto ocasiona su muerte impune, su condición de nuda vida. Surge en los testimonios una estrategia macabra, nutrida de cientos y cientos de jóvenes pobres y excluidos, sin posibilidades y perspectivas de presente digno; jóvenes que a la vuelta de la esquina fácilmente son encontrados para ser seducidos y conducidos a un mundo deshumanizado, que, aunque abyecto, se configura en posibilidad y opción de vida para la mayoría.

Un último segmento centra la atención en las conclusiones que aportan en la construcción de políticas públicas de los procesos de desvinculación e inclusión a la vida civil de esta población, teniendo en cuenta parámetros diferenciales y factores multidimensionales en el marco de la heterogeneidad que caracteriza la juventud.

\section{Vulnerabilidad y reclutamiento forzado}

Establecer la relación entre vulnerabilidad y reclutamiento forzado implica partir del concepto de vulnerabilidad, entendiéndola como una situación y, a la vez, como un proceso: una situación que puede denotar fragilidad extrema para un sector particular de la población y un proceso susceptible de ser reversible o evitable (Rodríguez, 2015). Cualquiera de las posibilidades alude directamente a condiciones que, al brindar o negar el contexto, darían como resultado la vulneración sistemática de los derechos o el potencial de desarrollo humano, máxime cuando de las tempranas inversiones que se hagan en la niñez dependerá en gran modo las perspectivas para el futuro (PNUD, 2014).

Debido a las condiciones que desde las últimas décadas vienen afectando la calidad de vida de los jóvenes en América Latina y el Caribe, el concepto de vulnerabilidad ha ganado cada vez más presencia en los estudios sociales, programas de atención y planeación en políticas públicas en el continente. Cada vez con más fuerza la juventud se está viendo sometida a un panorama desolador frente a las perspectivas de desarrollo y movilidad social. Un estudio que revela este panorama es el realizado por el Banco Mundial, Ninis en América Latina, el cual confirmó que en 2016 se cuentan aproximadamente veinte millones de jóvenes latinoamericanos en edades de quince a veinticuatro años que no estudian ni trabajan.

Colombia no es ajena a esta realidad. Según el informe, el país ocupa el segundo lugar en Latinoamérica, precisando que "el problema de los ninis puede estar vinculado al crimen y a la violencia, lo que aumenta los riesgos para los jóvenes y la sociedad en su conjunto" (De Hoyos, Rogers y Székely, 2016). A su vez, detalla que casi el $60 \%$ de los ninis provienen de los hogares más pobres y vulnerables, y que el $66 \%$ de esta población son mujeres. Estas cifras indican para el país cómo las desigualdades sociales y las brechas de género existentes distan considerablemente de ser resueltas, conformándose a su vez 
en factores que precipitan la vinculación de los jóvenes a grupos al margen de la ley.

Son varios los estudios desarrollados en Colombia que han identificado la relación intrínseca entre reclutamiento y vulnerabilidad social (ICBF, 2012; Defensoría del Pueblo, 2006). Entre las variables identificadas, se encuentran la pobreza y marginalidad en la que crecieron los jóvenes; la presencia de distintas formas de violencias en escenarios de socialización como la familia y la escuela, aunado a la convivencia cotidiana con actores armados en sus territorios; y, por último, la construcción de imaginarios sociales e identidades masculinas y femeninas mediadas por la militarización de la vida civil.

Dichos aspectos son enunciados por los testimonios como los principales factores que motivaron o influyeron en su vinculación, ello en tanto elementos de orden estructural entretejidos a sus experiencias vitales. Por las situaciones que día a día enfrenta la juventud en escenarios marcados por la precariedad, "hablar y aproximarnos al concepto de vulnerabilidad social implica tratar de acércanos a los fenómenos de desigualdad y pobreza desde una visión integral y multidimensional" (González, 2009, p. 13). Un análisis que, para el caso a tratar, resulta notable por la influencia directa en la construcción de proyectos de vida para estos jóvenes excombatientes. A continuación, se exponen varios apartes de los relatos que ponen en evidencia esta condición:

En mi familia siempre hemos sido muy pobres. Mi papá, muy irresponsable, hizo sufrir mucho a mi mamá; incluso a ella se le murió una niña y todo por la pobreza en la que vivíamos, y así fuimos de casa en casa, mi papá nunca fue la persona que quisiera darnos un hogar [...] yo llevé muy mala vida. (Mujer participante 4)

Otro de los relatos manifiesta: "Más que todo de vivir estos tiempos fue vivir las necesidades, eso me obligaba a, muchas veces, asumir cosas que en mi edad no debían ser" (Hombre participante 2).

De esta manera, la pobreza con la que crecieron en su infancia desembocó en que tuvieran que asumir tareas u oficios no correspondientes con su edad cronológica y mental. Es así como desde los diez u once años empezaron a ejercer el trabajo infantil, teniendo que abandonar sus hogares, desertando del sistema educativo para cubrir necesidades personales y convertirse en sostén económico. Tomar desde temprana edad estos roles implicó enfrentar la vida desde una mirada adulta, crecer de manera acelerada truncando los deseos, sueños o expectativas que se tenían con respecto a sí mismos y en relación con las opciones que el contexto ofrecía. Los testimoniantes comparten al respecto:

Eso era algo duro porque cuando en la casa se tenía para el desayuno, no teníamos para la comida, o a veces no teníamos nada, nos tocaba pasarla o salir a rebuscar- nos por ahí qué se conseguía, entonces complicado, por lo menos usted siendo un niño. Mi pensado era entrar, porque a mí también me dijeron que me iban a dar un sueldo y eso, pues yo dije trabajar y lo que me paguen le mando a mi viejita, pero pues no fue así. (Hombre participante 3)

Por otro lado, se afirma que:

No pude estudiar todo lo que tenía que estudiar, estudie hasta tercero de primaria, ahí me humillaban porque me tocaba ir descalza a la escuela. De ahí empecé a trabajar en cultivos de tomate, cohombro y así me ganaba el jornal, ocho mil o diez mil pesos; después empecé a trabajar en casas de familia, también me humillaban. (Mujer participante 4)

Por la vulnerabilidad social y económica presente en las familias de origen de estos jóvenes, se instituye como un componente influyente para la vinculación de la niñez al trabajo, que incluye una de sus peores formas, el reclutamiento forzado (OIT, 2013). Al tener que salir del sistema escolar para dedicarse al "rebusque", se condicionaron notablemente las probabilidades de ascenso social, convirtiendo al grupo armado como la única opción para la consecución de este fin. Estos factores, en palabras de José Manuel Valenzuela (2015) resultan ser una de las principales condiciones del juvenicidio que:

tiene como antecedente la obliteración de los canales de movilidad social de las y los jóvenes. Estamos hablando de horizontes de vida restringidos tanto en términos de empleos disponibles, como en su capacidad para superar la línea de pobreza. Los jóvenes son los más afectados por el desempleo y el subempleo, situación que los coloca en la necesidad de acceder a la informalidad y la paralegalidad, condiciones de precarización que engrandecen la alternativa de las actividades ilegales como opciones disponibles para adquirir diversos bienes básicos y simbólicos publicitados hasta el hartazgo, por los medios de comunicación como elementos que definen las vidas exitosas. Sin embargo, la mayoría de las y los jóvenes se encuentran excluidos de esos estilos de vida y de las opciones de consumo promovidas por el neoliberalismo. (p. 10)

En este análisis, se integra con las voces de los jóvenes participantes:

Por cometer el error de cogerle el revólver a mi papá a escondidas para venderlo; tenía muchas ganas de comprarme unas zapatillas, que valían como unos setenta mil pesos, pero como no tenía los recursos, entonces ellos me dijeron que me las compraban, que mejor dicho yo ganaba bueno, que me fuera con ellos, que incluso tenía un valor de ochocientos o un millón. (Mujer participante 1) 
Y también:

Yo empecé a trabajar desde muy niño, en ese tiempo me pagaban a cinco mil el día, trabajaba de seis de la mañana a cinco de la tarde, eso era en el campo, era cortando bambú o caña brava. Pasé al punto donde trabajé en un aserrío, de ahí pues me desesperaba de ver a mi viejita sufriendo, y no me gustaba verla así, no me gustaba sentirme así ante la necesidad, entonces buscaba la forma de ganarme algunos pesos, de tener para la semana. (Hombre participante 3 )

Las circunstancias propias de este contexto privativo sirven como caldo de cultivo para que los grupos armados activen diferentes estrategias de coacción y seducción, ofreciendo a los jóvenes una vida de lujos, un trabajo fácily lucrativo que rápidamente garantiza poder, el acceso a las armas para la conquista del estatus de reconocimiento y respeto. Son vanas promesas que se conectan en muchos sentidos con los imaginarios que se han interiorizado desde la infancia, donde prima cierta sacralización a la imagen del guerrero y la atracción por símbolos propios de la guerra; así, formar parte de un grupo armado se convierte en una expectativa de vida (Chávez y Romero, 2008). El siguiente relato amplía el análisis:

En parte hay reclutamiento en el sentido de manipulación o de comprar, muchas veces llegaba uno a un pueblo cuando necesitaba así gente, llegaba uno a los pueblos y miraba así gente que eran como más fáciles de acceder para que pudieran ingresar, entonces uno llegaba por ese punto, más que todo se le llegaba a la gente necesitada, sí, los pelados que andan por ahí, varados, sin plata. Entones ahí es donde uno aprovecha y llega el punto en ofrecerles cosas, ofrecerles plata, que van a tener una vida relajada, que van a tener lo que quieren, más que todo lo de las viejas; si son viejas se les dice que van a tener su sueldo, y eso pasa, entonces esa es la clase o la parte más fácil de ingresar personal a la organización. (Hombre participante 3)

A las condiciones de pobreza y exclusión social a la que estaban expuestos se sumaba la carencia afectiva junto con la violencia intrafamiliar. La desestructuración familiar caracterizada por formas de relacionamiento autoritario y un marcado desequilibrio en las relaciones de poder entre sus miembros agudizaba el panorama vivido; fueron así sus contextos familiares los que progresivamente alentaron la idea de pertenecer a los grupos armados asentados en sus territorios como una opción real y cercana de escape a las vulneraciones infringidas y la debilidad de los lazos construidos en las relaciones filiales, considerando que "las necesidades psicoafectivas, de protección, seguridad y autoestima, como las de aprendizaje y experiencias de logro en estos niños / as y adolescentes, no pudieron ser satisfechas, primando las carencias, abandonos, fracasos y diferentes grados de maltrato" (Conace, 2005, p. 19). Los participantes comparten:

El impulso tal vez fue el cariño que nunca tuve, de pronto, de mi mamá; cuando yo era muy niño ella me pegaba por todo, una vez me cogió con un lazo, me dejo todo morado, no me podía ver hablando así con otros niños porque me entraba; yo le cogí rabia a mi mamá porque cuando estábamos estudiando, creo que íbamos a salir de quinto de primaria, se hizo un paseo, entonces yo le rogué a mi mamá pa' que me dejara ir, le llore, de todo hice y no, que no y que no; desde ese momento le cogí (silencio) rencor, ya después fue cuando empecé los problemas con mi mamá, ya peleaba mucho con ella, ya no me dejaba mandar, no me dejaba pegar, pues yo creo que todo eso fue porque me hizo falta el cariño de mi mamá. (Hombre participante 3)

Otro afirma: "Lo que me motivo a irme al grupo fue el maltrato de mi papá, también a dejar el colegio, el maltrato era bastante, por miedo a lo que me fuera a hacer" (Mujer participante 1).

Esta lógica de vida a la que muchos jóvenes se van adhiriendo responde, en buena medida, a las formas como se van conformando las identidades militarizadas, entendiendo que la naturalización de las violencias permea su construcción, siendo el arma un símbolo de poder y estatus, el cual adquiere gran fuerza como opción de vida para muchos jóvenes. A estas circunstancias se añade el papel que empieza a cobrar el grupo armado ilegal, el cual brinda cohesión y sentido de pertenencia; un lugar en el que van formando y construyendo los soportes cognitivos y morales frente a sí mismos y la realidad que les rodea. Es en este contexto donde, a punta de fuerza e imposición, llegan a alcanzar el reconocimiento que en muchos otros escenarios sociales les ha sido negado. Uno de los relatantes manifiesta:

Entonces ya empezaron a decir que por qué no me iba, que me iban a pagar bien, que iba a tener plata, que iba a tener armas, que no sé qué, bueno, en sí a mí siempre me gustaron las armas, sí, yo desde pequeño, no sé yo era uno de los que jugaba con mis amiguitos que a los soldados, sí, todo eso, digamos mi sueño era ser un soldado, yo decía que cuando fuera más grande quería ser soldado, y pues ahí empezaron a pintarme todo eso y pues yo los veía a ellos, por ejemplo, que la pasaban bien ahí en el pueblo, con esos carros bacanos, con esas mujeres tan lindas, entonces yo dije "pero porque no puedo tener todo eso sí ellos son personas como yo”. (Hombre participante 2)

En otro relato se afirma:

Soy aficionado como quien dice a las armas, entonces las ganas, como quien dice tener poder; pero me nació 
más cuando llegaron al pueblo, que uno los veía con sus fusiles, cuando a veces en las noches salían a echar plomo, me nacía cada vez más esas ganas de estar ahí, de ser parte del grupo. (Hombre participante 3)

Finalmente, otro relato menciona que:

Ya la gente me tenía respeto a pesar de que yo era pelada, pues yo era, yo me sentía orgullosa porque cargaba un arma, porque en ese pueblo nosotros éramos la ley [...] en un pueblo delante de todo mundo, y, o sea, la gente imagínese nunca había habido policía y eso ver un arma a la gente le producía mucho temor. (Mujer participante 1)

Así las cosas, podría afirmarse que el reclutamiento no solo es forzado por la utilización de la violencia y las formas de coacción para enlistar a los jóvenes, sino que es forzado por la pobreza, el continuum de violencias, la discriminación y negación de posibilidades para esta población. Los aspectos descritos con base en los relatos de vida de los participantes destacan el entrecruzamiento de diferentes factores económicos y socioculturales que en variadas formas conducen al reclutamiento forzado, cuyo trasfondo atiende a la desigualdad histórica que afecta negativamente la vida de uno de los grupos poblaciones más vulnerados del país. La juventud, periodo vital que idealmente podría configurar sueños, retos y posibilidades, en la actual realidad social es símbolo de desesperan$\mathrm{za}$, proyectos frustrados y, dolorosamente, muerte artera.

\section{La vida armada como escenario del juvenicidio}

Aproximarse al juvenicidio como práctica sistemática de eliminación física y simbólica de ciertos agrupamientos y sectores de la juventud en Colombia, pasa necesariamente por el análisis de un fenómeno que atraviesa la historia reciente del país: el conflicto armado interno que por más de cinco décadas impactó de manera dolorosa la vida de miles de jóvenes pobres, pertenecientes a sectores marginales e históricamente excluidos, discriminados y subalternizados, con un presente y futuro difuso. Bajo estas condiciones, son cada vez más los jóvenes que diariamente se ven involucrados en el espiral de violencias que operan los grupos armados, cuyas macabras estratagemas van instaurando la muerte impune de importantes segmentos de la población.

Por ser el juvenicidio una categoría antisistémica, se han planteado varios objetivos como constructo teórico y categoría política de análisis de la realidad social que padecen los jóvenes. José Manuel Valenzuela (2016) refiere que una de las posibilidades de esta categoría radica en visibilizar la gran cantidad de jóvenes asesinados en América Latina, haciendo notables sus pertenencias, adscripciones y repertorios identitarios como factores que originarían la sistematicidad de los asesinatos.
Bajo esta perspectiva teórica y política, el desarrollo de este apartado contempla el funcionamiento y las dinámicas sustentadas en un orden bio y necropolítico propio de los grupos armados ilegales a los que pertenecieron los jóvenes testimoniantes. Expone desde sus voces las experiencias de adaptación, adhesión y sobrevivencia a estas lógicas, imbuida en distintas expresiones del juvenicidio y devenida de la subalternidad que rodea la existencia de los jóvenes concebidos como nuda vida.

El juvenicidio se afirma en lo que Giorgio Agamben ha denotado como la nuda vida, "una vida a la que puede darse muerte impunemente" (2006, p. 180), la cual no configuraría delito o sanción. Una existencia carente de derechos, descartable, supeditada a la voluntad necropolítica del soberano, quien detenta el poder sobre la vida y la muerte. Dicha soberanía sostendría su posición totalizadora en "la capacidad para definir quien tiene importancia y quien no la tiene, quien esta desprovisto de valor y puede ser fácilmente sustituible y quién no" (Mbembe, 2012, p. 46). Bajo esa premisa, al interior de estos grupos armados los jóvenes son asumidos como objetos prescindibles, fácilmente reemplazados por su condición.

En este marco, los relatos describen ampliamente distintos lemas, prácticas y reglas que los combatientes debían seguir como normas que garantizaban su supervivencia en la hostilidad y los peligros propios de la guerra. Factores como la obediencia y el silencio se convertían en mecanismos para garantizar la vida; a su vez, mantenerse con vida implicaba que las ordenes fuesen ejecutadas automática o mecánicamente, no mediaban criterios personales más que el cumplimiento ciego. Un ejercicio del poder soberano, tanto fáctico como simbólico, un régimen vertical e impositivo donde silencio y obediencia se configuran en dispositivos que organizan eficazmente las relaciones y el orden de la vida militar. Las jóvenes comparten sus vivencias:

A mí lo que me daba moral también eran mis compañeros porque decían "obedezca, no más obedezca y verá que se le respeta su vida, y cumpla lo que tiene que hacer", o sea "haga esto" y lo hago, se tenía que obedecer. (Mujer participante 1)

\section{Otra afirma:}

Pues allá en el grupo la mayoría de personas decía que obedecer es vivir y en boca cerrada no entran moscas, o sea allá es la ley del silencio, usted allá vio algo, no sé, no sé nada, no sé quién sería, porque allá los mismos sapos lo hacen matar a uno. (Mujer participante 4)

Un antecedente clave en el entendimiento del juvenicidio se presentaría con la pérdida de ciudadanía de estos jóvenes, víctimas de reclutamiento forzado. Un proceso de desciudadanización (Moreno, 2014; Castro y Moreno, 
2015) que legitima y justifica su muerte impune bajo un orden necropolítico. Al ser los jóvenes combatientes desprovistos de su condición de ciudadanos y titulares de derechos, su eliminación no se constituye como delito, pues son sujetos "matables", convertidos en nuda vida, reducidos a la condición de sujetos sin valor alguno, llevando "una vida que nunca habrá sido vivida, que no es mantenida por ninguna consideración, por ningún testimonio, que no será llorada cuando se pierda" (Butler, 2010, pp. 32-33). A este respecto, los jóvenes indican:

A ellos lo que les importaba era el fusil y la remesa, que a uno lo podían matar, pero con tal de que no se perdiera el fusil, lo demás no importaba, si miraban a un compañero herido y miraban que no podía, le quitaban la remesa y el fusil y lo dejaban ahí tirado o lo remataban, ellos decían que un soldado se consigue en cualquier parte pero que un fusil es caro. (Mujer participante 1)

\section{Otro relatante afirma:}

Yo allí tuve que ver y escuchar cómo gente del grupo mataba a gente del mismo grupo que por una cagada, que por disociación de la organización, por jodas así que a veces no tenían ni sentido, que porque llegaba borracho, por eso los mataban, entonces uno ahí estaba que podía morir por manos de la misma organización. (Hombre participante 2)

Son, en síntesis, necropolíticas propias del modelo económico capitalista que afectan con más anuencia la vida y el cuerpo de los jóvenes. Achille Mbembe (2012) explica la necropolítica a partir del modelo colonialista en que el poder soberano define qué grupos sociales o personas son prescindibles, es decir, quiénes deben morir y quiénes merecen vivir. Es, por consiguiente, un sistema suscrito en la desigualdad. Desde esta perspectiva teórica, los juvenicidios son expresión continuada de la necropolítica para resguardar uno de sus máximos propósitos: el mantenimiento intacto de los dictámenes e intereses capitalista, colonialista y patriarcal, los cuales sitúan a los jóvenes en espacios determinados, bajo roles prescritos y formas de expresarse, acordes con la visión constreñida de dichos sistemas. Cabe considerar la voz de una joven participante:

Son las reglas de allá, allá uno no puede sentir compasión por nadie, ni siquiera por los compañeros de uno que van a matar, porque le dicen a uno que sí siente mucho dolor se va con él, así entonces le toca a uno hacerse el duro así le duela, así a uno le duela por la muerte de otras personas le toca a uno hacerse el que no. (Mujer participante 4)

Dentro de este marco, un elemento que reluce en los relatos es la presencia de la crueldad como hecho cotidiano, una práctica que termina naturalizada y percibida como normal. De esta manera, se desarrolla una pedagogía de la crueldad ejercida contra el bando oponente y al interior de las mismas estructuras armadas, la cual es concebida como práctica orientadora del disciplinamiento corporal de los combatientes, como "una forma de poder simultáneamente individualizante y totalizadora" (Foucault, 1983, pp. 213-234). La deshumanización se expresa en castigos ejemplarizantes, torturas y todo tipo de prácticas que comportan una violencia extrema. Todos estos sirven como mecanismos para probar la fidelidad y grado de adhesión a la organización, cumpliendo los mandatos y el orden vertical establecido en la organización, un escenario en que el asomo de escrúpulos o compasión son tajantemente sancionados. Rita Segato (2016) describe las lógicas propias como se potencia la fuerza expresiva de estas prácticas, ya que:

En la acción paraestatal de estos grupos es todavía más crucial la necesidad de demostrar esa ausencia de límites en la ejecución de acciones crueles, ya que no se dispone de otros documentos o insignias que designen quién detenta la autoridad jurisdiccional. Por un lado, la truculencia es la única garantía del control sobre territorios y cuerpos, y de los cuerpos como territorios, y, por otro, la pedagogía de la crueldad es la estrategia de reproducción del sistema. (2016. pp. 61-62)

Los siguientes apartes sirven para la ampliación del análisis desarrollado:

Yo ahorita me acuerdo de eso y se me eriza la piel, o sea me da, me da como vaina, y nosotros éramos cagados de la risa, y así sucedía algo, que cualquier otra cosa, que mataban a alguien, y nosotros éramos riéndonos, que a usted lo van a matar, que lo van a mandar pa' donde Pedro a que vaya a sembrar caña, asustando la gente, o sea trata que lo iban a matar o lo íbamos a matar entonces nosotros éramos riéndonos. Éramos felices causando dolor en la persona, sí, y ahí es donde yo digo que éramos desalmados, porque una persona que de verdad sea consciente de lo que hace no hace eso [...], eso es de tanto que lo trabajan a uno allá, uno se vuelve así, ya como que uno se acostumbra a eso, como que ya eso no importa, el trabajo es normal. (Hombre participante 2)

Por ello, las prácticas propias del entrenamiento militar involucran un adoctrinamiento a nivel corporal y psicológico, el cual garantiza, por un lado, el cumplimiento cabal de las órdenes que reciben los combatientes y, por otro, la demostración cabal de la adhesión al colectivo. Hacerse parte del grupo implica aprehender los gestos, miradas, posturas, actitudes y comportamientos que lo identifican. En definitiva, un lenguaje corporal interiorizado que 
prueba y comprueba la adopción univoca de los principios y valores característicos del guerrero.

Con esta finalidad, el adiestramiento es accionado con los dispositivos de control del biopoder y desplegados a través de la biopolítica en la gestión de sus cuerpos (Foucault, 1997; 2004). En tal sentido, "el propósito del dispositivo se vincula con el ejercicio del poder: orientar, controlar, administrar, gobernar comportamientos, sensibilidades y pensamientos de los sujetos" (Bomvinalli, 2015 , p. 84) a través de prácticas discursivas y simbólicas que legitiman su fin. Cabe recuperar la siguiente narración:

Uno allá aprende, como quien dice, a ser una piedra, ¿sí?, a como no tener sentimientos o a no expresar los sentimientos, porque usted los puede sentir como cualquier persona, usted tiene sus sentimientos y le da esa culpa o esa tristeza o esas ganas de llorar, pero entonces allá uno tiene que guardárselas, sí porque igual si uno mostraba esa, como esa culpa era complicado. (Hombre participante 3)

\section{Y también:}

En parte era lo que buscaban ellos, que fuera uno sanguinario, y eso es lo que buscan en eso, que sea uno sanguinario porque saben que usted ya después de que llega a ese punto, y ya se deja dominar es por la ansiedad de querer ver sangre, pues los favorece a ellos porque ya no le va a importar nada, ni la vida de uno mismo. (Hombre participante 2)

Ocasionar por primera vez la muerte a otra persona acarrea un profundo impacto psicológico en los jóvenes por la magnitud de la huella indeleble que ocasiona el hecho. Los relatos compartidos describen cómo en los meses siguientes al primer asesinato la imagen de lo acontecido quedaba fija en la memoria, ocasionando una serie de síntomas como trastornos del sueño y la alimentación, pesadillas, paranoia, entre otras manifestaciones que podían conducir a comportamientos como el gusto por ver sangre. Sin embargo, tiempo después hay una adaptación por la sistematicidad de estas acciones que pasan a ser concebidas como normales en la lógica de la guerra, dentro de lo que califican parte de su trabajo. Al respecto dos jóvenes comparten:

Yo estaba traumatizado, sí, nunca había hecho eso con una persona, pues ahí tocaba, porque de todas formas uno era de ahí, y en sí había una consigna que el que no hiciera lo mismo entonces era en contra o algo sospechoso, y entonces lo cogían a uno entre ojos; yo hacía lo mismo, y en sí uno tenía una psicología, allá a usted lo trabajan psicológicamente para matar, para perder el miedo, para tener la sangre fría, como se dice. (Hombre participante 2)

\section{El otro afirma:}

Entre más se va integrando usted al grupo pues como que más fácil se van dando las cosas, ya se adapta a todo y pues de ahí en adelante a lo que se viniera, que era cuando tocaba hacer cosas, que, a los castigos, las vacunas, los combates, cuando se mataba a las personas, lo más difícil de estar allá es cuando le dan la orden a usted de que tiene que matar a alguien, pero ya después con el tiempo se adapta al trabajo. (Hombre participante 3)

De otro lado, el juvenicidio moral conjuga las esferas de lo económico y lo simbólico. Esta alianza articularía elementos como la estigmatización territorial, el establecimiento de imaginarios sociales que bajo el miedo y la sospecha legitiman diferentes formas de violencia en contra de los jóvenes, activando una serie de dispositivos de control que terminan implantando las identidades deterioradas o identidades desacreditadas (Goffman, 1993), las cuales son construidas alrededor del ser joven, impactando tanto la posibilidad de construir proyectos de vida como en los sentimientos de desesperanza y frustración frente al presente, la idea de no futuro.

Carlos Feixa (2015) reflexiona alrededor del juvenicidio moral, tomando como referente la crisis económica de la última década en los países mediterráneos y su impacto en los proyectos de vida de la juventud española por la implementación de políticas neoliberales, la globalización de la pobreza y la desigualdad social; así:

Las condiciones de precariedad laboral, educativa, política, residencial y afectiva en la que viven muchos jóvenes [...] implican, de alguna manera la desaparición simbólica de la juventud como actor social, su invisibilización como protagonista en la escena pública, y la metamorfosis del periodo juvenil, que pasa de ser una dase de transición, a ser una fase intransitiva, como resultado de trayectorias fallidas, pendulares e interminables hacia la vida adulta. (pp. 204-205)

Así como se nota la presencia permanente de un juvenicidio gota a gota, también es posible hablar de una desciudadanización gradual en la que se van negando todo los derechos fundamentales y la posibilidad para que estos jóvenes se piensen un proyecto de vida sustentado en condiciones de libertad y dignidad. Lamentablemente, el juvenicidio que ronda la vida de los jóvenes es un proceso que no se provoca en la etapa de la juventud, es un proceso que se encuentra presente desde la misma gestación, cimentado en las raíces de la pobreza, el abandono y la ausencia de oportunidades de esos niños vulnerados que se convertirán en jóvenes subalternizados, presas de las violencias estructurales y directas como víctimas o victimarios. 


\section{Conclusiones}

Desigualdad y vulnerabilidad social son ejes orgánicos de la problemática multidimensional del reclutamiento forzado en Colombia. Plantear el análisis de este fenómeno en el segundo país más desigual de América Latina involucra retomar los componentes estructurales que han permitido su reproducción y consolidación. Uno de los ejes que articula la sistematicidad en la vinculación de los jóvenes en el conflicto armado y las estructuras ilegales a lo largo y ancho del país es, sin lugar a duda, la desigualdad social, la cual lejos de disminuirse se conforma en un factor transgeneracional que signa el presente y futuro de cada vez más generaciones víctimas del continuum de violencias reproducidas en variados contextos y escenarios.

Los elementos que anteceden el involucramiento de los jóvenes testimoniantes al conflicto armado atienden a variados factores de riesgo que responden a la vulnerabilidad y exclusión social de la que fueron víctimas. Se identifican disrupciones en la vida familiar y educativa con presencia de violencia intrafamiliar y deserción del sistema educativo; la pobreza y marginalidad conducente al trabajo infantil; el desarrollo de sus procesos identitarios reducidos a la influencia del estereotipo guerrero con insuficientes escenarios de interacción y socialización que permitan la participación social y el ejercicio de la ciudadanía. Asimismo, escasos horizontes de futuro más allá de la militarización y los imaginarios construidos en un entorno sociocultural que dificultó su adecuado desarrollo cognitivo y moral.

Desnaturalizar la vulnerabilidad debe ser un imperativo en las acciones que atañen a los programas, proyectos y políticas públicas dirigidas hacia la población juvenil. Para este propósito ético-político, es sustantivo demarcar los atenuantes políticos, culturales, socioeconómicos y simbólicos que rodean las vulneraciones históricas a los derechos humanos de esta población. Los hallazgos encontrados a partir de los testimonios indican que no se dan en razón de que los jóvenes sean vulnerables por naturaleza, sino que son resultado de la confluencia de una serie de factores que precipitaron su adhesión a los grupos armados de los que hicieron parte, pues "dicha situación o condición no genera efectos negativos per se, sino hasta que se ponen en marcha procesos de desprotección, o bien condiciones o situaciones que ponen en riesgo o dificultan el desarrollo del niño y sus derechos" (Rodríguez, 2015, p. 14).

Respecto al carácter voluntario de la vinculación de niños, niñas, adolescentes o jóvenes, la Corte Constitucional, en su Auto 251 de 2008, determina que este es simplemente aparente al ser "el resultado de la manipulación perversa y engañosa, por parte de los miembros de estas estructuras criminales de diversos y complejos factores de vulnerabilidad y presión materiales y psicológicos" (Corte Constitucional de Colombia, 2008). Esta consideración es fundamental en la aproximación al reclutamiento forzado; sin embargo, la indagación también debe pasar por entender las motivaciones que conducen a que ciertos segmentos de la población juvenil opten por la paralegalidad en una especie de fascinación e identificación con el modelo y la imagen del guerrero, cuyo marco es la militarización que ha permeado la vida cotidiana tras más de cinco décadas de conflicto armado.

La militarización de la vida civil se ha constituido en uno de los mayores impactos que ha devenido con el conflicto armado en Colombia. Las transformaciones en las formas de relacionamiento, en las dinámicas y lógicas que guiaban la vida, cristalizaron los daños culturales que trajo consigo la violencia en los territorios y las zonas más azotadas por la presencia de los grupos armados, naturalizando así los símbolos propios de la guerra y convirtiendo en legitimas las prácticas y métodos de apropiación de los recursos bajo el poder de las armas.

Este es el escenario en el que han crecido los jóvenes participes de esta investigación. La atmosfera ideal para la implantación del juvenicidio, "producto y conclusión de diversas formas de precarización económica, social, cultural e identitaria de jóvenes que devienen prescindibles a partir de su situación social y sus repertorios de identidad" (Valenzuela, 2016). Inmersos en la dimensión bio y necropolítica de los grupos armados, los jóvenes sobreviven como guerreros a través del disciplinamiento de sus cuerpos, la desensibilización emocional frente al dolor y la pedagogía de la crueldad como normas de conducta que reproducen los factores dinamizadores del mismo fenómeno.

\section{Referencias}

Agamben, G. (2006). Homo sacer, el poder soberano y la nuda vida. Madrid: Pretextos.

Bomvinalli, A. (2015). El código de faltas de la provincia de Córdoba (Argentina) como dispositivo de poder. La construcción de la seguridad a partir de la equivalencia simbólica "joven pobre=peligroso". Controversias y Concurrencias Latinoamericanas, 7(11), 81-101.

Butler, J. (2010). Marcos de guerra. Las vidas lloradas. Barcelona: Paidós.

Castro, M. y Moreno, H. (2015). Corrupción e impunidad versus justicia y derecho en México. En: J. Valenzuela (Coord.), Juvenicidio: Ayotzinapa y las vidas precarias en América Latina y España. Barcelona: Ned Ediciones.

Chávez, Y. y Romero, Y. (2008). El juego de la guerra, niños, niñas y adolescentes en el conflicto armado en Colombia. Tabula Rasa, 8, 197-210. https://doi. org/10.25058/20112742.328

Conace (2005). Modelo de intervención en personas con consumo problemático de sustancias psicoactivas, recluidas en los establecimientos penitenciarios chilenos. Santiago: Ministerio del Interior. 
Correa, R. (1999). La aproximación biográfica como opción epistemológica, ética y metodológica. Proposiciones, 29, 35-44.

Corte Constitucional de Colombia (2008). Auto $251 \mathrm{de}$ 2008. Recuperado de https://www.corteconstitucional.gov.co/T-025-04/AUTOS\%202008/101.\%20 Auto\%20del\%2006-10-2008.\%20Auto\%20251.\%20 Protecci\%C3\%B3n\%20ni\%C3\%B1os,\%20ni\%C3\%B1as\%20y\%20adolescentes.pdf

De Hoyos, R., Rogers, H. y Székely, M. (2016). Ninis en América Latina: 20 millones de jóvenes en busca de oportunidades. Washington D.C.: Grupo Banco Mundial. Recuperado de https://guzlop-editoras.com/web_ des/ineco/empleojuv/pld3039.pdf

Defensoría del Pueblo (2006). Caracterización de las niñas, niños y adolescentes desvinculados de los grupos armados ilegales: inserción social y productiva desde un enfoque de derechos humanos. Recuperado de https://www.unicef.org/colombia/media/2396/ file/Caracterizaci\%C3\%B3n $\% 20 \mathrm{de} \% 20 \mathrm{ni} \% \mathrm{C} 3 \%$ B1ez\%20desvinculada.pdf

Feixa, C. (2015). El juvenicidio moral de los jóvenes... al otro lado del charco. En: J. Valenzuela (Coord.), Juvenicidio: Ayotzinapa y las vidas precarias en América Latina y España. Barcelona: Ned Ediciones.

Foucault, M. (1983). The subject and power. En H. Dreyfus y P. Rabinow (eds.), Michel Foucault. Beyond Structuralism and Hermeneutics. Chicago: University of Chicago Press.

Foucault, M. (1997). Il faut defendre la societé. Cours au Collège de France 1975-1976. Paris: Seuil.

Foucault, M. (2004). Securité, territoire, population. Cours au Collège de France 1977-1978. Paris: Seuil.

Goffman, E. (1993). El estigma. La identidad deteriorada. Buenos Aires: Amorrortú Editores.

González, L. (2009). Lecturas sobre vulnerabilidad y desigualdad social. Córdoba, Argentina: Universidad Nacional de Córdoba. Centro de Estudios Avanzados - Conicet. Recuperado de http://biblioteca.clacso.edu.ar/Argentina/ cea-unc/20100825121333/Lecturasvulnerabilidad.pdf

Instituto Colombiano de Bienestar Familiar ICBF (2012). Vulnerabilidad, reclutamiento y utilización de niños, niñas y adolescentes por grupos armados organizados al margen de la ley. Recuperado de https://www. icbf.gov.co/sites/default/files/publicacion-26.pdf

Instituto Colombiano de Bienestar Familiar [ICBF] (2013). Niños, niñas y adolescentes desvinculados ICBF.

Llovet, V. (2015). Políticas y violencias en clave generacional en Argentina. En: J. Valenzuela (Coord.), Juvenicidio: Ayotzinapa y las vidas precarias en América Latina y España. Barcelona: Ned Ediciones.
Mbembe, A. (2012). Necropolitica seguido de sobre el gobierno privado indirecto. Madrid: Editorial Melusina.

Moreno, H. (2014). Desciudadanizacióny estado de excepción. Andamios. Revista de Investigación Social, 11(24), 125-148. https://doi.org/10.29092/uacm.v11i24.235

Muñoz, G. (2015). Juvenicidio en Colombia: crímenes de Estado y prácticas socialmente aceptables. En: J. Valenzuela (Coord.), Juvenicidio: Ayotzinapa y las vidas precarias en América Latina y España. Barcelona: Ned Ediciones.

Observatorio de Memoria y Conflicto (2019). Infografía de reclutamiento y/o utilización de niños, niñas y adolescentes. Recuperado de http://centrodememoriahistorica.gov.co/observatorio/wp-content/ uploads/2018/08/Runna_15-09-18.pdf

Organización Internacional del Trabajo OIT (2013). Informe mundial sobre el trabajo infantil: vulnerabilidad económica, protección social y lucha contra el trabajo infantil. Recuperado de https://www.ilo.org/ ipec/Informationresources/WCMS_178449/lang-es/index.htm

Programa de las Naciones Unidas para el Desarrollo PNUD (2014). Informe sobre el Desarrollo Humano 2014. Sostener el progreso humano: reducir vulnerabilidades y construir resiliencia. Recuperado de https://www.undp.org/content/dam/undp/library/ corporate/HDR/2014HDR/HDR-2014-Spanish.pdf

Revista Semana (2015). Una dura radiografía del campo colombiano. Recuperado de http://www.semana.com/economia/articulo/campo-colombiano-en-la-pobreza/438618-3

Rodríguez, R. (2015). Vulnerabilidad y derechos de la niñez en América Latina. Buenos Aires: Clacso.

Segato, R. (2016). La guerra contra las mujeres. Madrid: Traficantes de Sueños.

Sistema Nacional de Información en Juventud y Adolescencia en Colombia (2018). Violencia intrafamiliar jóvenes. Recuperado de http://obs.colombiajoven. gov.co/Observatorio/Observatorio.aspx?rpt=3zg/ DyRZnRM7b4wjjeLANA==

Unidad de Víctimas (2019). Registro Único de Víctimas.

Valenzuela, J. (2015), Remolinos de viento: juvenicidio e identidades desacreditadas. En: J. Valenzuela (Coord.), Juvenicidio: Ayotzinapa y las vidas precarias en América Latina y España. Barcelona: Ned Ediciones.

Valenzuela, J. (2016). Juvenicidio: necropolítica y iuvenis sacer. En: S. Borelli, Jóvenes latinoamericanos: necropoliticas, culturas políticas y urbanidades. Inédito.

\section{(®) $(\Theta 0$}

